\title{
The Assessment on Road Capacity and Level of Service: The Case of Western Shewa Zone Ambo Town, Oromia Regional State, Ethiopia
}

\author{
Wosen Woldemichael \\ Department of Civil Engineering, Ambo University Institute of Technology
}

\begin{abstract}
The increasing number of population and vehicles has a negative impact on the capacity and operating condition of road facilities. Congestion and delay are the major problems related to capacity and level of service of road segment in the city. This is a major concern to travelers, administrators, merchants, developers and the community at large. This issue is now days a great concern for Ethiopia and major cities in the country like Ambo town. From these major towns in Ethiopia, Ambo town is now the concern for this study. This study mainly tries to assess the capacity and qualitatively describe the performance and level of service of selected road segments in Ambo town. The research involves both quantitative and qualitative approaches. Quantitative data and analysis were used to determine the level of service of the selected road segments. As a data source both primary data and direct field measurements, mainly volume count, Speed and travel time survey and also secondary data were the main sources of quantitative data. I have selected three representative sections to study the capacity and level of service. And the segments are classified a sub-urban street under interrupted flow type according to the Highway capacity manual 2000. From the analysis the selected segments are performing well in terms of level of service analysis. The lowest level of service is LOS D and the highest level of service is LOS C. The capacity analysis result shows the capacity of the segment is not well at all for the selected segment. To improve the capacity of the segments the Town should improve well designed roadway with sufficient number of lane and lane width and proper improvement of parking areas for vehicles.
\end{abstract}

Keywords: Level of Service, Capacity, HCM 2000

DOI: $10.7176 / C E R / 11-8-01$

Publication date:September $30^{\text {th }} 2019$

\section{INTRODUCTION}

1.1. Background of the study.

Capacity and Level of service are two related terms. Capacity analysis tries to give a clear understanding of how much traffic a given transportation facility can accommodate. Level of service tries to answer how good the present traffic situation on a given facility is. Thus LOS analysis gives a qualitative measure of traffic, whereas capacity analysis gives a quantitative measure of a facility. Infrastructure development in Africa is very poor, lagging behind the rest of the world in terms of quality and access. The situation is worse in poor countries like Ethiopia, where abundant of problems have made the supply of physical infrastructure and services to continually lag behind the urban population growth rate. World Development Report (2006)

Ambo is one of the towns in Ethiopia experiencing rapid population growth and requires greater infrastructure provision. Currently due to rapid population growth some of the city road, including the road to be discussed in this research have inadequate capacity to allow the traffic movement over them. This is because of some cross sectional design problems including travel way, pedestrian, bicycle lane, median and other cross sectional elements. In Ambo town there are different road facilities which include interrupted flow types. This research contains the evaluation of capacity and Level of Service for selected road segment of Ambo town road facilities.

\subsection{Statement of the Problem}

In analysis of road capacity and level of services there are many problems to be solved. In this research we try to solve problems which may causes due to improper estimation of road capacity and level of services and also we check the designed geometric is whether sufficient to accommodate the present traffic flow or not. There are many problems arose due to traffic congestions in ambo town. Road traffic jams continue to remain a mojor problem in most cities around the world,especially in developing regions resulting in massive delays, incrased fuel wastage and monetary losses.Due to the poor lane decipline common out come in many developing regions is the presence of small critical areas; poor traffic management around those hotspots potentially results in elongated traffic jams.

Now a days the road network in Ambo town cannot keep up with the growing volume of traffic. The traffic congestion level has been increasing significantly in the last few years and this trend seems to continue. At certain times of day,traffic volumes increase, the driving speed decreases and roads get congested.On the other hand, the road capacity is poor which resulted in difficult for mobility and the moving of heavy trucks through the town is the main problem for level of service. In general, poor road capacity and level of service affects road 
quality,mobility and environmental safety. The main problems such as lane discipline, Absence of traffic signals, Parking improvement, Lane width...etc and sub problems such as increasing delay time, increasing traffic accident, not maintain acceptable level of services, less performance, aabsence of traffic signals...etc. Parking is one of the major problems that is created by the increasing road traffic. It is an impact of transport development. The availability of less space in urban areas has increased the demand for parking space especially in areas like Central business district. This affects the mode choice also.

The increasing numbers of population and vehicles have a negative impact on the capacity and operating condition of road facilities in Ambo town. Congestion and delay are the major problems related to capacity and level of service of road segment in the town. Traffic flows is reasonably well when the flow rate is less than capacity, but excessive delay and congestion can occur when the flow rate is at or near capacity. In Ambo town traffic congestion has negative effect on road uses day to day activities. This negative effect was not evaluated well before and the causes are not studied well. Recently traffic congestion in the study area becomes a problem to the road users by limiting the mobility of the road facility and by increasing delay and fuel consumption. Vehicles traveling along a road segment encounter a variety of situations that cause them to slow slightly or even come to a stop. These encounters delay and cause their segment running time to increase. Situations that can cause this delay include vehicles turning from the segment, pedestrians crossing at a mid-segment crosswalk, vehicles maneuvering into or out of an on-street parking space, and double-parked vehicles blocking a lane. Hence to reduce the problem stated above the town administration is working to improve the traffic operation by constructing new roads.

\subsection{Significant of the Study}

It is clearly stated in the objective that the main goal of the study is to assess the capacity and level of service of selected road segments in Ambo town. The study has two major significance to the town administration and transportation facility planners. Firstly; it helps in identifying that the selected road segments are performing above or below the estimated capacity it is constructed for. Identifying this issue is an important step to classify the road as congested or not and to take necessary measures to overcome it. Secondly; the study can also be used as a useful resource in the future planning of transportation facilities in the town. In addition to the above mentioned points the purpose of measuring capacity and level of service is to improve transportation services for users.

\subsection{Objective of the Study}

1.4.1 General objective

The overall aim of this research is the assessment on road capacity and level of service the Case of Western Shewa Zone Ambo Town, Oromia Regional State, Ethiopia..

\subsubsection{Specific objectives}

The specific objectives of this study are:

$>$ To determine the capacity of road segment.

$>$ To assess the level of service of the roadway segment.

$>$ To find the composition of vehicle in each stretch.

$>$ To determine the present capacity of the road and thereby determining the volume to capacity ratio in each mid-block or section.

$>$ To find the level of service of the entire roadway.

\subsection{Scope of the Study}

The scope of the study was limited to Ambo town roads. After counting the road segments based on HCM 2000 definition, two representative sections are taken to study the capacity and level of service based on the traffic volume. The study focuses on the selected road sections and does reflects the town's road capacity and level of service. The procedure employed to evaluate capacity and level of service for the segment is based on the Highway Capacity Manual 2000. Although the manual is not fully applicable for developing countries like Ethiopia, due to the unavailability of such a manual in the country the Highway capacity manual is the only option left. And the segments are classified as sub-urban street under interrupted flow type according to the Highway capacity manual 2000 .

\section{RESEARCH METHODOLOGY}

In this part the researcher tried to mention the research methodology- including the research design, data collection techniques and tools and analysis methods which have been used to carry out this research and they are listed and discussed briefly below.

\subsection{Method of data collection}

In this research the methods followed were designed in such a way that the key questions of the research be 
answered properly. The research involves both quantitative and qualitative approaches. Quantitative data and analysis were used to determine the level of service of the selected road sections. As a data source both primary data or direct field measurements and secondary data were the main sources of quantitative data. A reconnaissance study was conducted with the aim of understanding the problem associated with capacity and level of service on the highway. It was also conducted to assist in identifying the data that could be collected on the field and also the method used to collect it.

\subsubsection{Primary data source}

A two hour volume count will be gathered in the selected road sections in the peak hours of the day. These are at the morning, afternoon and in the evening time. Different filed measurement will also be gathered as per the procedure to meet the objective.

Traffic Volume Counts: For this project a short term 2 hour traffic count of vehicles travelling in both directions of the street that is towards the selected segment of Ambo town. In the town the road facilities maximum hourly rate occurs mainly in the morning peak hours from 7:30am up to 9:30am when peoples start their daily activities and in the afternoon peak hours of from 11:30am up to 1:30am and in the evening peak hours of 5:00pm and 7:00pm. Main method that was used is the manual count method.

Field measurement: We also take field measurement in order to analysis road capacity and level of services. We use tape to measure such as lane width, lateral clearance and distance from traveled way to obstruction and length of segment

\subsubsection{Secondary data source}

We collected secondary data from Traffic Police Office of Ambo town and Ambo town Municipality. Therefore mentioned offices provided us with necessary data on the segment length and miscellaneous data required.

\subsection{Description of Bus station to Awura godana (kisose)}

According to the volume count survey result bus station to Awuro godana segment is the more vehicle volume counted segment one in the town or has high capacity when compared to others. There are no traffic signals in both directions in order to control traffic movements. It is the location where more traffic is accommodated.

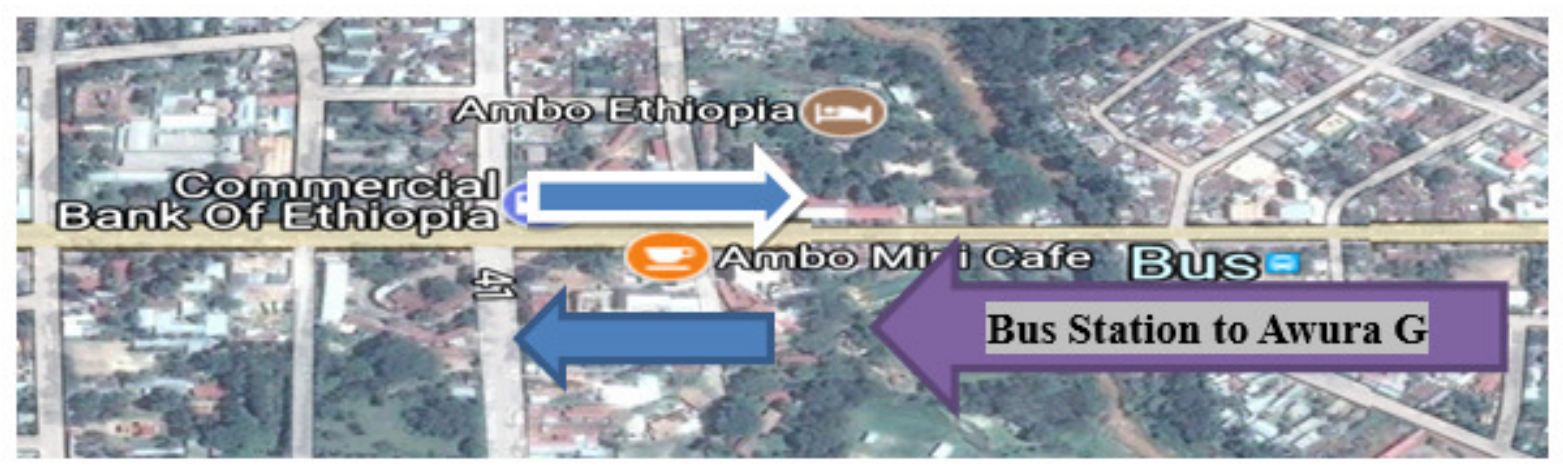

Source: http://www.google.com/AmboMap, Ethiopia

Figure 1. Map description from Bus station to Awura Godana

\subsection{Description of Bus station to Main campus}

Bus station to main campus section vehicle volume counted has less capacity, when compared to above selected section. It has not traffic signals which control the movements of different type vehicles.

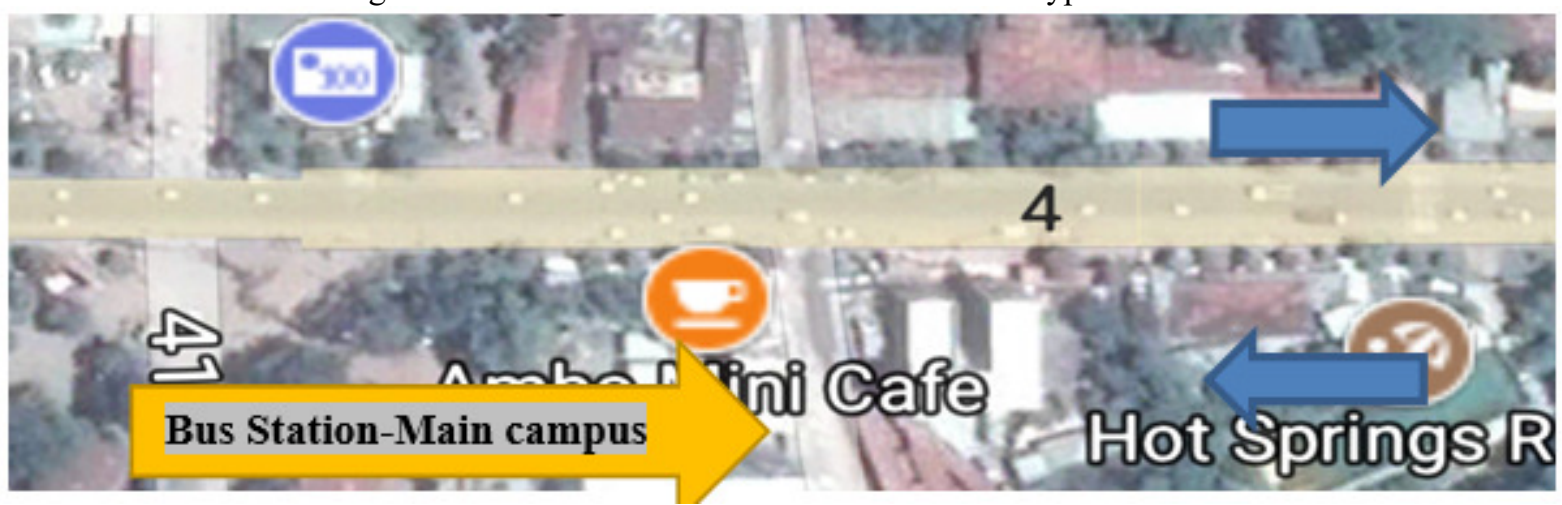

Source: http://www.google.com/AmboMap, Ethiopia

Figure 2: Map description from Bus station to Main campus 


\subsection{Data Analysis}

The data collected during the field study was presented in traffic volume data sheets and speed sheet as shown in the appendix using Microsoft excel worksheet. Once all this has been done the analysis will include analysis level of service of the section of the highway.

\section{RESULT AND DISCUSSION}

\subsection{Capacity Analysis}

\subsubsection{Traffic Volume and Flow Pattern Analysis}

\section{Passenger Car Unit Analysis}

Passenger car unit analysis is important because it considers different characteristics like width, length and height that cause serious variations in the traffic stream. Due to this difference each type of vehicle has distinct effect on the traffic steam. Therefore the PCU is important because it compare the effect of different vehicle with respect to single car. The result is summarized in the Table 1 below. Finally the factors was used for the computation of traffic volume in terms of passenger car unit for the selected segments.

Table 1: Passenger Car Unit factor

\begin{tabular}{|c|c|c|c|c|c|c|c|c|c|}
\hline \multirow[t]{2}{*}{ Direction } & \multirow[t]{2}{*}{ Cart } & \multirow[t]{2}{*}{$2 w$} & \multirow[t]{2}{*}{$3 w$} & \multirow[t]{2}{*}{ Car } & \multicolumn{3}{|c|}{ Bus } & \multirow[t]{2}{*}{ truck } & \multirow[t]{2}{*}{ trailer } \\
\hline & & & & & Mini & medium & large & & \\
\hline PCU & 4 & 0.5 & 0.8 & 1 & 2 & 2 & 2 & 3.5 & 3.5 \\
\hline
\end{tabular}

\section{Traffic Volume from Bus station to Awuro Godana}

This section is located at the center of the city and considered as the most congested by the road users' perception. The traffic count was done for $2 \mathrm{hr}$ of peak hour at the morning, afternoon and evening. On both directions the traffic flow is high at the peak hour survey. The traffic volume at the morning, afternoon and evening period at both directions was somehow uniform but the morning period volume is relatively higher than the afternoon and the evening period. The result for the morning peak hour is summarized in the Figure below.

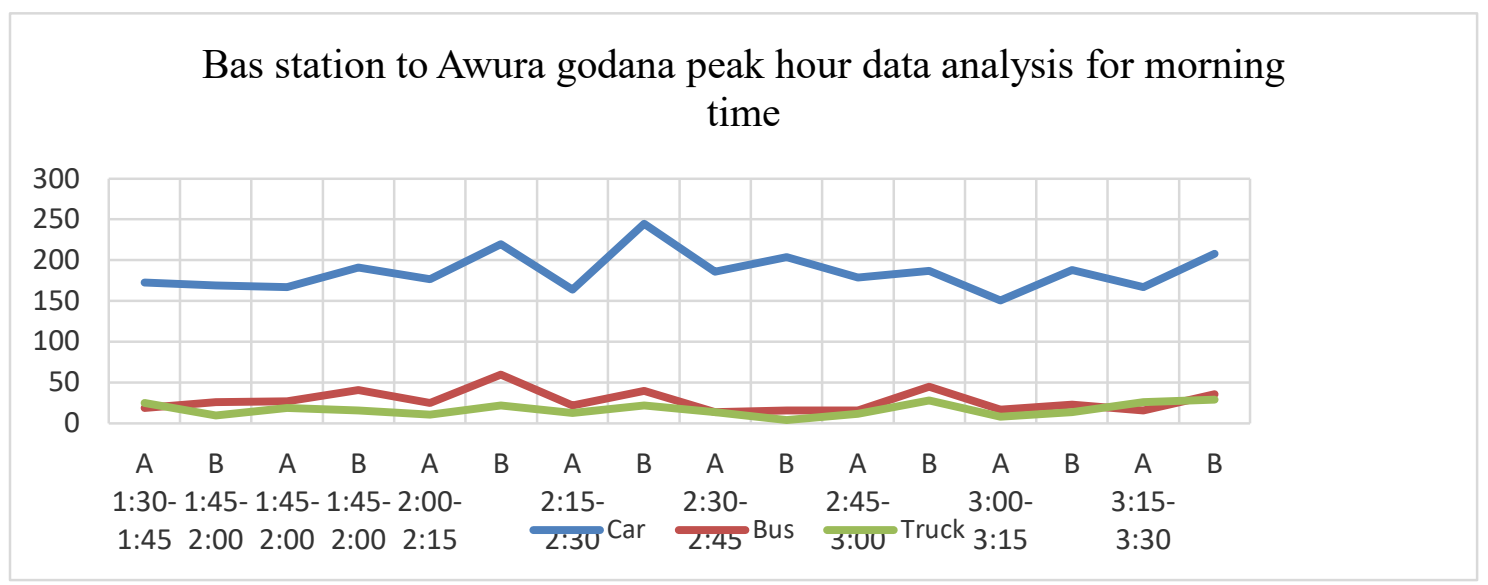

Where: $\mathrm{A}=$ Bus station-Awura godana and $\mathrm{B}=\mathrm{A}$ wura godana-Bus station

Figure 3: Traffic Volume at Bus station to Awura Godana section for morning peak

The figure below shows traffic composition of the week day by vehicle class. Accordingly, there exist 10,124 vehicles on this segment both directions out of this 8,227 vehicles or $82 \%$ of the total traffic is composed of car and other vehicles; such as: converted cart, $2 \mathrm{~W}, 3 \mathrm{~W}$ also Bus with moderately high compared commercial vehicle like trucks with very low volume. 


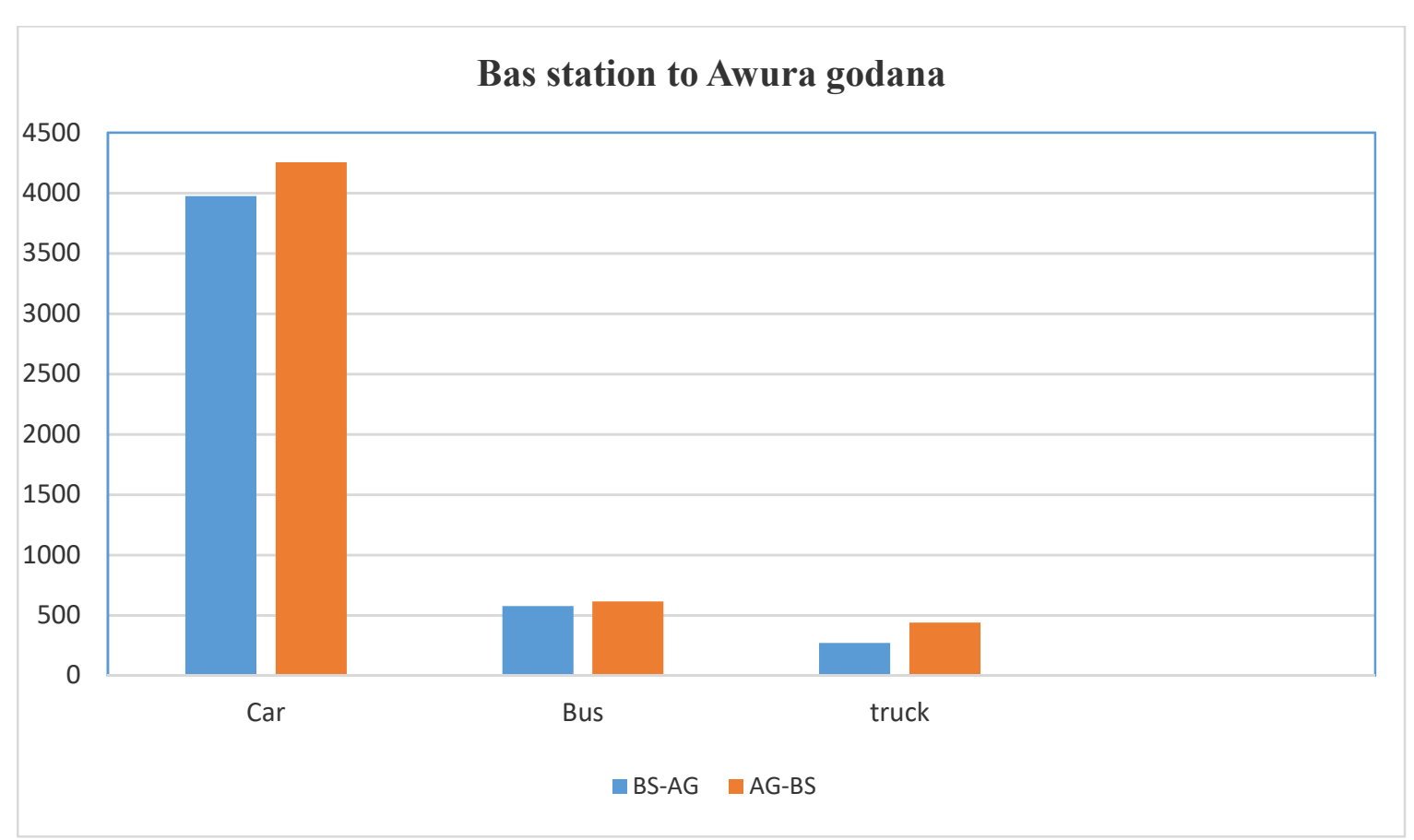

Where: $\mathrm{BS}=$ Bus station-Awura-godana and $\mathrm{AG}=$ Awura-godana Bus station

Figure 4 Traffic Volume Distribution by Vehicle Type on week day at at Bus station to Awura Godana section

\section{Traffic Volume at Bus station to main campus section}

This section is also located at the center of the town. The traffic count was done for $2 \mathrm{hr}$ of peak hour at the morning, afternoon and evening. On both directions the traffic flow is less as compared to the other section. The traffic volume at the morning, afternoon and evening period of peak hour at both directions was almost uniform but like the above the morning period volume is relatively higher than the afternoon and the evening period. The result for the morning peak hour is summarized in the Figure below.

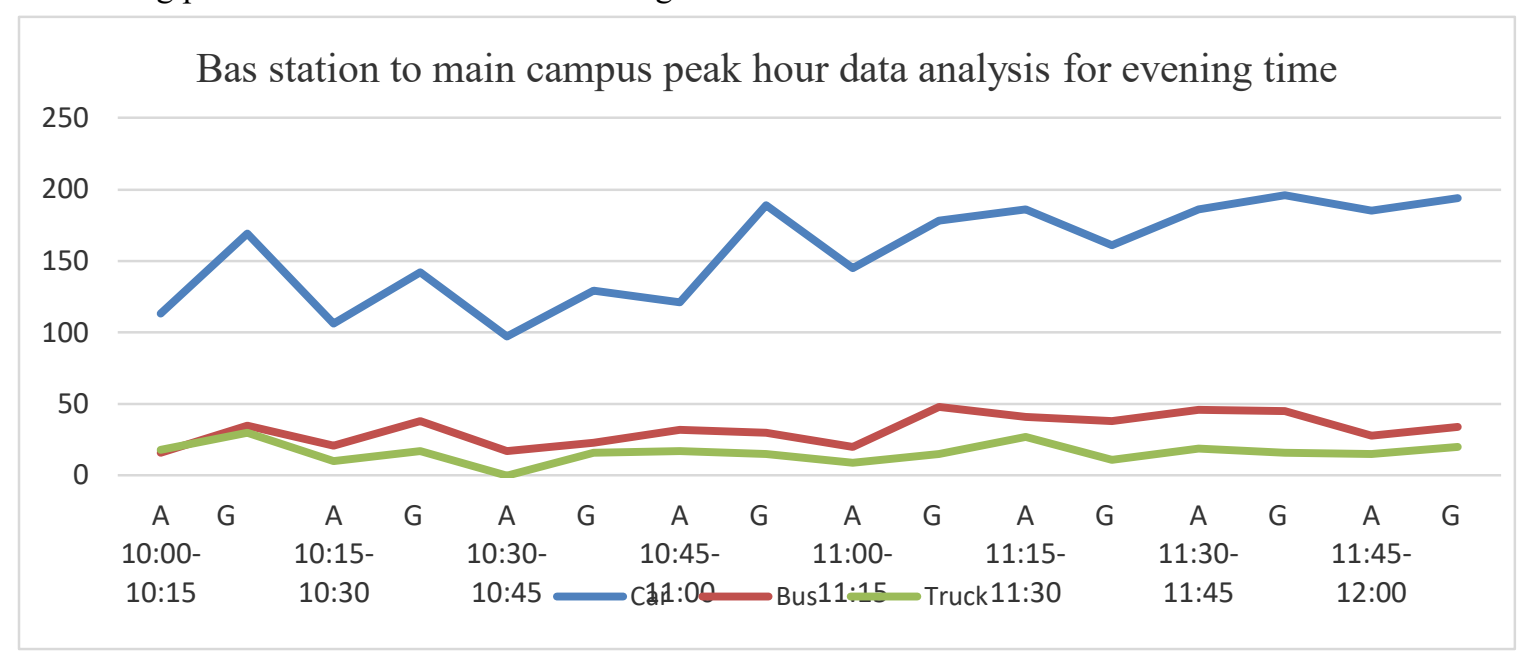

Where: $\mathrm{A}=$ Bus station-Main campus and $\mathrm{G}=$ main campus-Bus station

Figure 5 Traffic Volume at Bus station to Main Campus section

When I see the traffic composition from the total traffic of week day is 8,884 vehicles on the segment of both directions about 7,927 or $89 \% \%$ the total traffic is composed of car and other vehicles; such as: converted cart, $2 \mathrm{~W}$, and $3 \mathrm{~W}$ also Bus with moderately high compared commercial vehicle like trucks with very low volume. 


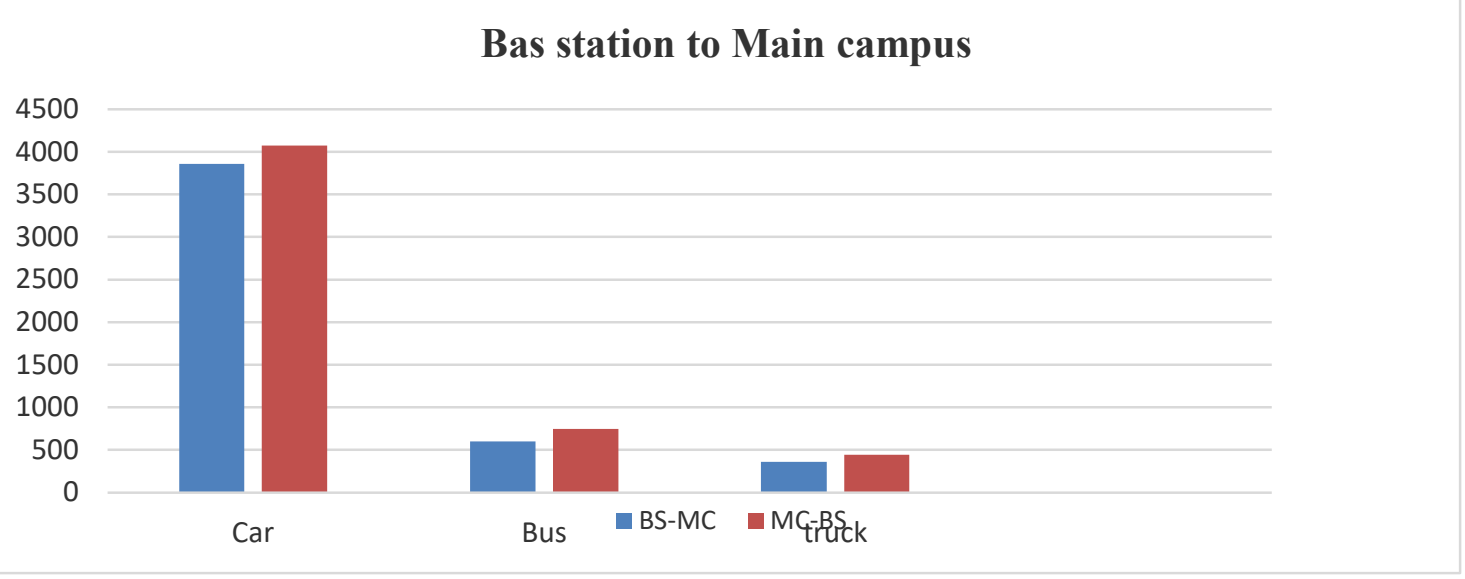

Figure 5 Traffic Volume Distribution by Vehicle Type on week day at at bus station to main campus section

Based on the results presented in section 4.1.1 traffic volume and flow pattern analysis the following points can be pointed out. The traffic count was done for $2 \mathrm{hrs}$ at the morning, afternoon and evening on each section for one days which are one from week day and the other from weekend. This days are selected from the traffic police feedback on which day that the vehicles are high for considering maximum volume. As an overall view the on all the two section the vehicle type dominated are car (cart, $2 \mathrm{~W}$ and $3 \mathrm{~W}$ ) and buses are less but moderate and trucks are very less.

\subsection{Analysis of Level of Service}

\subsubsection{Levels of Service}

For multilane highways, the measure of effectiveness used to define levels of service is density. The use of density, rather than speed, is based primarily on the relationship between density and level of services given on high way capacity manual.

To analysis the level of service we selected two road section in our research.

- Bus station to Awuro godana road section on both direction

- Bus station to main campus road section on both direction

\section{Bus station to Awurogodana road section on both direction}

At this station take the maximum peak hourly volume, which affects operational quality the road rather than other road section.

\section{Design Analysis}

There are two types of problems that are solved by capacity analysis. They are:

- Type I: Given the highway volume and the number of lanes, determine the maximum service flow rate and the level of service

- Type II: Given the highway volume and the level of service, determine the number of highway lanes required. Table 2 peak hourly volume of bus station to awuro godana of road section.

\begin{tabular}{|l|l|l|l|l|}
\hline Time & Bus and Truck & Recreational Cars & Total Vehicles per minute In both dire & $\begin{array}{l}\text { Total Vehicle } \\
\text { Per hour }\end{array}$ \\
\hline $11: 00-11: 15$ & 341 & 105 & 446 & \multirow{2}{*}{2004} \\
\hline $11: 15-11: 30$ & 384 & 106 & 490 & \\
\hline $11: 30-11: 45$ & 391 & 148 & 539 & \\
\hline $11: 45-12: 00$ & 406 & 123 & 529 & \\
\hline Total & 1522 & 482 & 2004 & \\
\hline
\end{tabular}

Table 3 description of collected data

\begin{tabular}{|l|l|}
\hline Description & Measurements $(\mathrm{m})$ \\
\hline Lane width & $11.51 \mathrm{ft}$ or $3.5 \mathrm{~m}$ \\
\hline Lateral clearance & $5 \mathrm{ft}$ or $1.5 \mathrm{~m}$ \\
\hline Obstruction from edge of shoulder & $5.129 \mathrm{ft}$ or $1.56 \mathrm{~m}$ \\
\hline Bus station to awurogodana(kisose) & $1096 \mathrm{~m}$ \\
\hline
\end{tabular}

Procedures for calculation of level of service:-

- Determination of peak hourly factors.

$$
\mathrm{PHF}=\frac{v}{v_{15} * 4}
$$


- Determination of service flow rate.

$$
\begin{gathered}
\mathrm{SF}=\frac{V}{P H F} \\
=\frac{2004}{0.929}=2157 \mathrm{veh} / \mathrm{hr}
\end{gathered}
$$

- Determination of maximum service flow rate.

The maximum service flow rate is determined as the product of the capacity under ideal conditions and the maximum volume-to-capacity ratio for the level of service $i$. as shown in equation below.

$$
\begin{gathered}
\mathrm{MSF}=\frac{V}{P H F * N * F_{W} * F_{H V^{*}} F_{P}} \\
\mathrm{PHF}=\text { Peak hour factor }
\end{gathered}
$$

$\mathrm{N}_{\mathrm{i}}=$ number of lanes (in one direction) required to provide level of service

$F_{W}=$ Adjustment Factor for the effect of restricted lane width and lateral clearance

$F_{P}=$ Driver Population Adjustment Factor

$F_{H V}=$ adjustment factor for presence of heavy vehicles

$\mathrm{V}=$ the highest hourly volume within a 24-hour period

To determine maximum service flow rate, first the above parameter must be calculated.

$>$ Determination of Adjustment Factor for the effect of restricted lane width and lateral clearance

\begin{tabular}{|c|c|c|c|c|c|c|}
\hline \multirow{4}{*}{$\begin{array}{c}\text { Distance from } \\
\text { Traveled } W / 2 y \\
\text { to Obstruction } \\
\text { (ft) }\end{array}$} & \multicolumn{6}{|c|}{ Adjustment Factor } \\
\hline & \multicolumn{3}{|c|}{ Obstructions on One Side } & \multicolumn{3}{|c|}{ Obscructions on Two Sides } \\
\hline & \multicolumn{6}{|c|}{ Lane Width" (ft) } \\
\hline & $\geq 12$ & 11 & 10 & 212 & 11 & 10 \\
\hline 26 & 1.00 & 0.95 & 0.90 & 1.00 & 0.95 & 0.90 \\
\hline 4 & 0.99 & 0.94 & 0.89 & 0.98 & 0.93 & 0.88 \\
\hline 2 & 0.97 & 0.92 & 0.88 & 0.95 & 0.90 & 0.86 \\
\hline $\mathbf{0}$ & 0.92 & 0.88 & 0.84 & 0.86 & 0.82 & 0.78 \\
\hline
\end{tabular}
This factor is used to adjust for lane widths less than $12 \mathrm{ft}$ and/or lateral clearance less than $6 \mathrm{ft}$. The following table gives the appropriate values for this factor for different lane widths and lateral clearances.

Table 4 Adjustment Factor for Restricted Lane Width and Lateral Clearance

The conditions in obstruction on two sides and the distance from traveled way to obstruction is $5.129 \mathrm{ft}$. From the above table by interpolation the value of $F_{W}$ is 0.941 .

\section{$>$ Determination of driver Population Adjustment Factor}

Driver population adjustment factor is used to whether drivers familiar with the roadway or not be familiar with the route. This can have a significant impact on operations and the value range between 1 to 0 . In condition drivers familiar with route, the value of driver population adjustment factor shown in below.

Table 5: Adjustment Factor for Driver Population

\begin{tabular}{cc}
\hline Traffic Stream Type & Adjustment Factor $\left.U_{p}\right)$ \\
\hline $\begin{array}{c}\text { Weckday, commuter } \\
\text { (familiar users) } \\
\text { Recreational or other }\end{array}$ & 1.00 \\
\hline & $0.75-0.99$ \\
\hline
\end{tabular}

Determination of adjustment factor for presence of heavy vehicles

Large trucks, buses, and recreational vehicles have performance characteristics (slow acceleration and inferior braking) and dimensions (length, height, and width) that have an adverse effect on roadway capacity. The other factor for presence heavy vehicles are types of terrains and passenger car equivalent have an adverse effect on roadway capacity. This road section has level characteristics. Hence the values of ER and ET are1.2 and 1.5 respectively.

Table 6 passenger car equivalent

\begin{tabular}{c|c|c|c}
\hline \multirow{2}{*}{ Factor } & \multicolumn{3}{|c}{ Type of Terrain } \\
\cline { 2 - 4 } & Level & Rolling & Mountainous \\
\hline$E_{T}$ & 1.5 & 2.5 & 4.5 \\
$E_{R}$ & 1.2 & 2.0 & 4.0 \\
\hline
\end{tabular}




$$
f_{H V}=\frac{1}{1+P_{T}\left(E_{T}-1\right)+P_{R}\left(E_{R}-1\right)}
$$

Also percentage of recreational cars and percentage of bus and truck determined.

$$
\begin{array}{r}
P_{R}=\frac{1522 * 100}{2004}=76 \%=0.76 \\
P_{T}=\frac{482 * 100 \%}{2004}=24 \%=0.24 \\
f_{H V}=\frac{1}{1+P_{T}\left(E_{T}-1\right)+P_{R}\left(E_{R}-1\right)} \\
=\frac{1}{1+0.24(1.5-1)+0.76(1.2-1)} \\
=0.786 \\
\text { Therefore, MSF }=\frac{V}{P H F * N * F_{W} * F_{H V} * F_{P}} \\
2004
\end{array}
$$$$
\begin{gathered}
=\frac{0.929 * 2 * 0.941 * 0.786 * 1}{}=1458 \mathrm{veh} / \mathrm{hr}
\end{gathered}
$$

\section{- Determination of Free flow speed}

FFS for multilane highways is the mean speed of passenger cars operating in flow rates up to 1400 passenger cars per hour per lane ( $\mathrm{pc} / \mathrm{h} / \mathrm{ln})$. If FFS is to be estimated rather than measured, the following equation can be used, which takes into account the roadway characteristics of lane width, lateral clearance, presence (or lack) of a median, an access frequency.

$$
F F S=B F F S-f_{L W}-f_{L C}-f_{M}-f_{A}
$$

Where, FFS = estimated free-flow speed in $\mathrm{mi} / \mathrm{h}$, BFFS = estimated free-flow speed, in $\mathrm{mi} / \mathrm{h}$, for base conditions,

$\mathbf{f}_{\mathbf{L W}}=$ adjustment for lane width in $\mathrm{mi} / \mathrm{h}$,

$\mathbf{f}_{\mathbf{L C}}=$ adjustment for lateral clearance in $\mathrm{mi} / \mathrm{h}$,

$\mathbf{f}_{\mathbf{M}}=$ adjustment for median type in $\mathrm{mi} / \mathrm{h}$, and

$\mathbf{f}_{\mathbf{A}}=$ adjustment for the number of access points along the roadway in $\mathrm{mi} / \mathrm{h}$

\section{Base free-flow speed}

A base free-flow speed of $60 \mathrm{mi} / \mathrm{h}$ may be used for rural and suburban multilane highways, if no field data is available. It may also be estimated using the posted speed limit. The base free-flow speed is approximately $7 \mathrm{mi} / \mathrm{h}$ higher than the posted speed limit, for speed limits of 40 and $45 \mathrm{mi} / \mathrm{h}$. and for speed limits of 50 and $55 \mathrm{mi} / \mathrm{h}$, the base free-flow speed is approximately $5 \mathrm{mi} / \mathrm{h}$ higher than the limit. The posted-speed-limit is $55 \mathrm{mi} / \mathrm{hr}$

$$
\begin{aligned}
\mathrm{BFFS} & =\text { Posted-speed-limit }+5 \mathrm{mi} / \mathrm{hr} \\
& =55+5=60 \mathrm{mi} / \mathrm{hr}=60 \mathrm{mil} / \mathrm{hr}
\end{aligned}
$$

\section{Adjustment for lane width}

The base condition for lane width is an average width of $12 \mathrm{ft}(3.65 \mathrm{~m})$ or greater. For narrower lanes, the base free-flow speed is reduced by the factors shown in Table

In condition $11 \mathrm{ft}$ lane width, the value of reduction in free-flow speed $\left(F_{L W}\right)$ is shown in below.

Table 7 Adjustment to Free-Flow Speed for Lane Width on a Freeway

\begin{tabular}{c|c}
\hline Lane Width (ft) & $\begin{array}{c}\text { Reduction in Free-Flow } \\
\text { Speed, } \boldsymbol{f}_{\mathbf{L W}}(\mathrm{mi} / \mathrm{h})\end{array}$ \\
\hline 12 & $\mathbf{0 . 0}$ \\
11 & 1.9 \\
10 & 6.6 \\
\hline \multicolumn{2}{c}{} \\
\multicolumn{2}{c}{$F_{L W}=1.9 \mathrm{mi} / \mathrm{hr}$}
\end{tabular}

\section{Adjustment for lateral clearance}

The adjustment factor for potentially restrictive lateral clearances $\left(\mathbf{f}_{\mathbf{L C}}\right)$ is determined first by computing the total lateral clearance, which is defined as In condition four lane multilane highway of lateral clearance $5 \mathrm{ft}$, the value of adjustment for lateral clearance is provides in shown below by interpolation. 
Table.8 Adjustment to Total Lateral Clearance on a Multilane Highway

\begin{tabular}{|c|c|c|c|}
\hline \multicolumn{2}{|c|}{ 4-Lane Multilane Highways } & \multicolumn{2}{|c|}{ 6-Lane Multilane Fighways } \\
\hline $\begin{array}{c}\text { Total Lateral } \\
\text { Clearance } \\
\text { (ft) } \\
\end{array}$ & $\begin{array}{l}\text { Reduction in Free- } \\
\text { Flow Speed, } f_{\mathrm{Lc}}(\mathrm{mi} / \mathrm{h})\end{array}$ & $\begin{array}{l}\text { Total Lateral } \\
\text { Clearance } \\
\text { (ft) }\end{array}$ & $\begin{array}{l}\text { Reduction in } \\
\text { Free-Flow } S_{\text {peed, }} \\
f_{\mathrm{LC}}(\mathrm{mi} / \mathrm{h})\end{array}$ \\
\hline $\begin{array}{r}\geq 12 \\
10 \\
8 \\
6 \\
4 \\
2 \\
0\end{array}$ & $\begin{array}{l}0.0 \\
0.4 \\
0.9 \\
1.3 \\
1.8 \\
3.6 \\
5.4\end{array}$ & $\begin{array}{r}\geq 12 \\
10 \\
8 \\
6 \\
4 \\
2 \\
0\end{array}$ & $\begin{array}{l}0.0 \\
0.4 \\
0.9 \\
1.3 \\
1.7 \\
2.8 \\
3.9\end{array}$ \\
\hline
\end{tabular}

\section{Median Adjustment type}

$$
\mathrm{f}_{\mathrm{LC}}=1.55 \mathrm{mi} / \mathrm{hr}
$$

Values for the adjustment factor for median type is depend on divide, two-way left-turn lane and undivided of multi-lane of highway. In condition undivided median type the value of reduction in free flow speed is shown in below.

Table 9 Adjustment to Free-Flow Speed for Median Type

$$
\mathrm{f}_{\mathrm{M}}=1.6 \mathrm{mi} / \mathrm{hr}
$$

\begin{tabular}{l|c}
\hline Median Type & Free-Flow Speed, $\boldsymbol{f}_{M}(\mathrm{mi} / \mathrm{h})$ \\
\hline Undivided & 1.6 \\
TWLTLs & 0.0 \\
Divided & 0.0 \\
\hline
\end{tabular}

\section{Access-Point Density Adjustment}

A critical adjustment to base free-flow speed is related to access-point density. Access-point density is the average number of signalized driveways or roadways per mile that provide access to the multilane highway on the right side of the roadway (for the subject direction of traffic).

Table 10 Adjustment to Free-Flow Speed for Access-Point Density

\begin{tabular}{c|c}
\hline $\begin{array}{c}\text { Access Density } \\
\text { (Access Points/Mi) }\end{array}$ & $\begin{array}{c}\text { Reduction in Free- } \\
\text { Flow Speed, } \mathbf{f}_{\mathbf{A}}(\mathbf{m i} / \mathbf{h})\end{array}$ \\
\hline 0 & 0.0 \\
10 & 2.5 \\
20 & 5.0 \\
30 & 7.5 \\
$\geq 40$ & 10.0 \\
\hline
\end{tabular}

$$
\mathbf{f}_{\mathbf{A}}=0 \mathrm{mi} / \mathrm{hr}
$$

Therefore, $\quad F F S=B F F S-f_{L W}-f_{L C}-f_{M}-f_{A}$

$$
\begin{gathered}
=60-1.9-1.55-1.6-0 \\
=54.95 \mathrm{mi} / \mathrm{hr} \\
\approx 55 \mathrm{mi} / \mathrm{hr}
\end{gathered}
$$

\section{- Determination of density}

$$
\begin{gathered}
\mathrm{D}=\frac{\mathrm{V}_{\mathrm{P}}}{\mathrm{FFS}}=\frac{\mathrm{MSF}}{\mathrm{FFS}} \\
=\frac{1458 \mathrm{veh} / \mathrm{hr}}{55 \mathrm{mi} / \mathrm{hr}} \\
=26.5 \mathrm{veh} / \mathrm{mi} / \mathrm{ln}
\end{gathered}
$$

Determination of level of service based on calculated maximum density and free flow speed criteria. In condition free flow speed $55 \mathrm{mi} / \mathrm{hr}$ and maximum density $27 \mathrm{veh} / \mathrm{mi} / \mathrm{ln}$ the level of services shown below. 
Table 11 level of service

\begin{tabular}{|c|c|c|c|c|c|}
\hline \multirow[b]{2}{*}{ Criteria } & \multicolumn{5}{|c|}{ Level of Service } \\
\hline & $\mathbf{A}$ & $\mathbf{B}$ & $\mathbf{C}$ & $\mathbf{D}$ & $\mathbf{E}$ \\
\hline \multicolumn{6}{|c|}{ Free-Flow Speed $=60 \mathrm{mi} / \mathrm{h}$} \\
\hline $\begin{array}{l}\text { Maximum density }(\mathrm{pc} / \mathrm{mi} / \mathrm{ln}) \\
\text { Minimum speed }(\mathrm{mi} / \mathrm{h}) \\
\text { Maximum v/c } \\
\text { Maximum service flow rate }(\mathrm{pc} / \mathrm{h} / \mathrm{In})\end{array}$ & $\begin{array}{l}11 \\
60.0 \\
0.30 \\
660\end{array}$ & $\begin{array}{c}18 \\
60.0 \\
0.49 \\
1,080\end{array}$ & $\begin{array}{l}26 \\
59.4 \\
0.70 \\
1,550\end{array}$ & $\begin{array}{l}35 \\
56.7 \\
0.90 \\
1,980\end{array}$ & $\begin{array}{c}40 \\
55.0 \\
1.00 \\
2,200\end{array}$ \\
\hline \multicolumn{6}{|c|}{ Free-Flow Speed $=55 \mathrm{mi} / \mathrm{h}$} \\
\hline $\begin{array}{l}\text { Maximum density }(\mathrm{pc} / \mathrm{mi} / \mathrm{hn}) \\
\text { Minimum speed }(\mathrm{mi} / \mathrm{h}) \\
\text { Maximum v/c } \\
\text { Maximum service flow rate }(\mathrm{pc} / \mathrm{h} / \mathrm{ln})\end{array}$ & $\begin{array}{c}11 \\
55.0 \\
0.29 \\
600 \\
\end{array}$ & $\begin{array}{c}18 \\
55.0 \\
0.47 \\
990 \\
\end{array}$ & $\begin{array}{c}26 \\
54.9 \\
0.68 \\
1.430\end{array}$ & $\begin{array}{l}35 \\
52.9 \\
0.88 \\
1,850\end{array}$ & $\begin{array}{r}41 \\
51.2 \\
1.00 \\
2,100 \\
\end{array}$ \\
\hline \multicolumn{6}{|c|}{ Free-Flow Speed $=50 \mathrm{mi} / \mathrm{h}$} \\
\hline $\begin{array}{l}\text { Maximum density }(\mathrm{pc} / \mathrm{mi} / \mathrm{ln}) \\
\text { Minimum speed }(\mathrm{mi} / \mathrm{h}) \\
\text { Maximum v/c } \\
\text { Maximum service flow rate }(\mathrm{pc} / \mathrm{h} / \mathrm{ln})\end{array}$ & $\begin{array}{c}11 \\
50.0 \\
0.28 \\
550 \\
\end{array}$ & $\begin{array}{l}18 \\
50.0 \\
0.65 \\
900 \\
\end{array}$ & $\begin{array}{c}26 \\
50.0 \\
0.65 \\
1,300\end{array}$ & $\begin{array}{c}35 \\
48.9 \\
0.86 \\
1,710\end{array}$ & $\begin{array}{r}43 \\
47.5 \\
1.00 \\
2,000\end{array}$ \\
\hline \multicolumn{6}{|c|}{ Free-Flow Speed $=45 \mathrm{mi} / \mathrm{h}$} \\
\hline $\begin{array}{l}\text { Maximum density }(\mathrm{pc} / \mathrm{mi} / \mathrm{ln}) \\
\text { Minimum speed }(\mathrm{mi} / \mathrm{h}) \\
\text { Maximum v/c } \\
\text { Maximum service flow rate }(\mathrm{pc} / \mathrm{h} / \mathrm{ln})\end{array}$ & $\begin{array}{l}11 \\
45.0 \\
0.26 \\
490\end{array}$ & $\begin{array}{l}18 \\
45.0 \\
0.43 \\
810\end{array}$ & $\begin{array}{c}26 \\
45.0 \\
0.62 \\
1,170\end{array}$ & $\begin{array}{l}35 \\
44.4 \\
0.82 \\
1,550\end{array}$ & $\begin{array}{c}45 \\
42.2 \\
1.00 \\
1,900\end{array}$ \\
\hline
\end{tabular}

Therefore, from the above the highway provides level of service D.As calculated level of service the road section characterized by unstable operation and significant delay. Such operations may be due to some combination of adverse progression and high volume. The volume-to capacity ratio is no greater than 1.0

1. Bus station to Main Campus road section on both direction

At this station we take the maximum peak hourly volume, which affects operational quality of the road rather than other section.

Table 12 description of collected data

\begin{tabular}{|c|c|}
\hline Description & Measurements $(\mathrm{m})$ \\
\hline Lane width & $11.51 \mathrm{ft}$ or $3.5 \mathrm{~m}$ \\
\hline Lateral clearance & $5 \mathrm{ft}$ or $1.5 \mathrm{~m}$ \\
\hline Obstruction from edge of shoulder & $5.129 \mathrm{ft}$ or $1.56 \mathrm{~m}$ \\
\hline Bus station to Main Campus & $1800 \mathrm{~m}$ \\
\hline
\end{tabular}

Table 13 Peak hourly volume of bus station to main campus of road section.

\begin{tabular}{|c|c|c|c|c|}
\hline Time & Bus and Truck & Recreational Cars & $\begin{array}{c}\text { Total Vehicles per minute } \\
\text { In both dire }\end{array}$ & $\begin{array}{c}\text { Total Vehicle } \\
\text { Per hour }\end{array}$ \\
\hline $11: 00-11: 15$ & 92 & 293 & 385 & \multirow{2}{*}{1743} \\
\hline $11: 15-11: 30$ & 117 & 317 & 434 & \\
\hline $11: 30-11: 45$ & 126 & 352 & 478 & \\
\hline $11: 45-12: 00$ & 97 & 349 & 1746 & \\
\hline Total & 432 & 1311 & & \\
\hline
\end{tabular}

Procedures for calculation of level of service:-

- Determination of peak hourly factors.

$$
\begin{gathered}
\mathrm{PHF}=\frac{v}{v_{15} * 4} \\
=\frac{1743}{478 * 4}=0.912
\end{gathered}
$$

- Determination of service flow rate.

$$
\begin{gathered}
\mathrm{MSF}=\frac{\mathrm{SF}=\frac{V}{P H F}}{P H F * N * F_{W} * F_{H V} * F_{P}} \\
f_{H V}=\frac{1}{1+P_{T}\left(E_{T}-1\right)+P_{R}\left(E_{R}-1\right)} \\
P_{T}=\frac{432 * 100 \%}{1743}=25 \%=0.25 \\
P_{R}=\frac{1311 * 100}{1743}=75 \%=0.75
\end{gathered}
$$




$$
\begin{gathered}
E_{T}=1.5 \\
E_{R V}=1.2 \\
=\frac{1}{1+P_{T}\left(E_{T}-1\right)+P_{R}\left(E_{R}-1\right)} \\
=0.784+0.75(1.2-1) \\
\text { Therefore, } \quad \begin{array}{c}
\mathrm{MSF}_{P}=\frac{V}{P H F * N * F_{W} * F_{H V} * F_{P}} \\
=\frac{1743}{0.912 * 2 * 0.941 * 0.784 * 1} \\
=1295 \mathrm{veh} / \mathrm{hr}
\end{array}
\end{gathered}
$$

- Determination of Free flow speed.

$$
\begin{gathered}
\mathrm{FFS}=\mathrm{BFFS}-\mathrm{f}_{\mathrm{LW}}-\mathrm{f}_{\mathrm{LC}}-\mathrm{f}_{\mathrm{M}}-\mathrm{f}_{\mathrm{A}} \\
\text { From the above analysis } \\
\text { BFFS }=60 \mathrm{mi} / \mathrm{hr} \\
\mathrm{f}_{\mathrm{LW}}=1.9 \mathrm{mi} / \mathrm{hr} \\
\mathrm{f}_{\mathrm{M}}=1.6 \mathrm{mi} / \mathrm{hr} \\
\mathrm{f}_{\mathrm{A}}=0 \mathrm{mi} / \mathrm{hr} \\
\mathrm{f}_{\mathrm{LC}}=1.55 \mathrm{mi} / \mathrm{h} \\
\mathrm{FFS}=\mathrm{BFFS}-\mathrm{f}_{\mathrm{LW}}-\mathrm{f}_{\mathrm{LC}}-\mathrm{f}_{\mathrm{M}}-\mathrm{f}_{\mathrm{A}} \\
=60-1.9-1.55-1.6-0 \\
=54.95 \mathrm{mi} / \mathrm{hr} \\
\approx 55 \mathrm{mi} / \mathrm{hr} \\
\mathrm{D}=\frac{V_{P}}{F F S}=\frac{M S F}{F F S} \\
=\frac{1295 \mathrm{veh} / \mathrm{hr}}{55 \mathrm{mi} / \mathrm{hr}}=23.5 \mathrm{veh} / \mathrm{mi} / \mathrm{ln}
\end{gathered}
$$

\begin{tabular}{|c|c|c|c|}
\hline & \multicolumn{3}{|c|}{$\begin{array}{l}\text { Design speed } \\
(\mathrm{km} / \mathrm{h})\end{array}$} \\
\hline & 70 & 60 & 50 \\
\hline$C_{j}(\mathrm{v} / \mathrm{h})$ & 2000 & 2000 & 1900 \\
\hline
\end{tabular}

- Determination of density

Based on Level of Service Criteria for Multilane Highways table the highway provides level of service C.

\subsection{Sizing a road using the Highway Capacity Manual approach}

When sizing a new roadway, a desired level of service is chosen by the designer. This value is then used in conjunction with a design traffic volume in order to select an appropriate cross-section for the highway (Martin Rogers- Highway-Engineering-Wiley-Blackwell (2003))

In given the highway volume and the level of service, it determines the number of highway lanes required. As calculated above the level of service of the Bus station to awuro godana segment become $\mathrm{D}$, which need sizing of road in order to increase capacity of the road and decrease congestion of traffic. In order to improve the capacity of road section that it needs sizing to maintain level of service B.

\section{Standard values taken from high way manual}

Table 14 Values of $\mathrm{Cj}$ for different design speeds

(Source: Highway Capacity Manual (TRB, 1985))

$\checkmark \quad$ Directional factor (D) $=0.65$

$\checkmark$ Design speed $(\mathrm{V})=60 \mathrm{~km} / \mathrm{hr}$

$\checkmark$ Capacity $(C)=2000 \mathrm{ve} / \mathrm{hr}$

$\checkmark$ Volume- capacity ratio $\left(\frac{V}{C}\right)=0.5$ 
Table 15 description of collected data

\begin{tabular}{|l|l|}
\hline Description & Calculated value \\
\hline Peak hour factor(PHF) & 0.912 \\
\hline Correction factor for highway env't $\left(F_{E}\right)$ & 0.9 \\
\hline Adjustment Factor for the effect of restricted lane width and lateral clearance $\left(F_{W}\right)$ & 0.941 \\
\hline Driver Population Adjustment Factor $\left(F_{P}\right)$ & 1 \\
\hline Adjustment factor for presence of heavy vehicles $\left(F_{H V}\right)$ & 0.472 \\
\hline
\end{tabular}

Procedures for sizing the road of highway is required to maintain level of service $B$

- Determination of directional design hour volume (DDHV)

$\mathrm{DDHV}=\mathrm{D} * \mathrm{DHV}$ (for multilane highway)

Where, $\mathrm{D}=$ Directional factor

$\mathrm{DHV}=$ Design hourly volume

DHV=PHV (Peak hourly volume)

From the above data $\mathrm{PHV}=2004 \mathrm{veh} / \mathrm{hr}$

So, $\mathrm{DDHV}=\mathrm{D} * \mathrm{DHV}=\mathrm{D} * \mathrm{PHV}=0.65 * 2004$

$$
=1302 \mathrm{veh} / \mathrm{hr}
$$

- Determination of service flow (SF)

$$
\begin{gathered}
\mathrm{SF}=\frac{D D H V}{P H F} \\
\text { Where, } \mathrm{PHF}=\text { Peak hour factor } \\
\mathrm{PHF}=0.929 \\
\mathrm{SF}=\frac{D D H V}{P H F}=\frac{1203}{0.929}=1403 \mathrm{veh} / \mathrm{hr}
\end{gathered}
$$

- Determination of number of lane $(\mathrm{N})$

$$
\mathrm{N}=\frac{S F}{C_{J} *\left(\frac{V}{C}\right) * F_{W} * F_{H V} * F_{P} * F_{E}}=\frac{1403}{2000 * 0.5 * 0.941 * 0.786 * 0.9}=\frac{1403}{666}=2.2 \approx 3
$$

Therefore, rounding up, three lanes are required in each direction to provide the level of service "B". Based on the results presented in section 4.1.2 traffic volume and flow pattern analysis the following points can be pointed out. The traffic count was done for $2 \mathrm{hrs}$ at the morning, afternoon and evening on each section for one days which are one from week day and the other from weekend. This days are selected from the traffic police feedback on which day that the vehicles are high for considering maximum volume.

As an overall view on the two sections the vehicle type dominated are car (cart, $2 \mathrm{~W}$ and $3 \mathrm{~W}$ ) and buses are less but moderate and trucks are very less.

\section{CONCLUSION AND RECOMMENDATIONS}

\subsection{Conclusions}

The following conclusions can be drawn from the study as a summary of the findings:

$>$ Traffic volume has the morning, afternoon and evening peak hour period for all segments. There is a huge traffic volume during evening peak hours on both directions on the street. This is as a result of more people go to their home.

$>$ It was observed that the higher percentage of traffic on the road section is comprised of Bajaj's. The automobiles and mini-buses are not as higher as compared to the Bajaj. It is moderate because automobiles are not financially affordable. And also buses and trucks are less in number.

$>$ On the selected two segments, the Level of service of the segment is performing well as per the guideline in HCM 2000. In the segments from Bus station to Main Campus which the Level of service is C but the other segments are moderate with Level of service D during peak hour durations.

$>$ The capacity analysis for the segment from Bus station to awuro godana is lowest compared to the other segments.

$>$ There exist less space in twon areas has increased the demand for parking space especially in areas like Central business district.

$>$ Capacity represents the ability of the system to handle trafic whereas level of service looks at the system from the drivers perspective.

4.1.2. Recommendations

To further enhance the results of this study the following recommendations are formulated:

$>$ Further research should be conducted to extend all aspects of this research, such as by collecting more data in order to improve results. From this data traffic volume is the one and it is recommended to count at least for seven consecutive days. Similarly during the collection of data it is better to use computerized devices to minimize human caused error. 
In order to maintain level of service B three lanes are required in each direction.

$>$ Further by using latest Highway capacity manual versions and using software programs other road segments can be analyzed.

$>$ From the analysis result, the capacity is lowest for segment from Bus station to Awuro godana compared to others. In order to improve the capacity the town administration should improve the road capacity by sizing existing road.

$>$ Town should improve well designed roadway with sufficient number of lane and lane width and proper improvement of parking areas for vehicles.

$>$ The city administration should provide to the signal in this segment especially for the segment for the segment from Bus station to Main campus. This improves the capacity of the segments and the traffic flow to be normal.

$>$ The Traffic Police Office of Ambo town should teaches all road user and the driver to know lane discipline in order improve the roadway capacity. Because of poor lane discipline the road capacity will reduce.

$>$ There should be some area exclusively allotted for parking which will be at some distance away from the main stream of traffic.

\section{REFERENCES}

- Africon Ltd. The East African Trade and Transport Facilitation project, (2011).http://www.dot.state.oh.us/districts/D06/project/71/Documents/DEL71\%20FeasIbility\%20Study

- Ashish kumar Patnaik (2013) "Level of Service Criteria of Roads in Urban Indian Context" MSc thesis National Institute of Technology, Rourkela Google map; http://www.google.com/AmboMap, Ethiopia. Highway Capacity Manual, HCM-2000, Transportation Research Board, Washington.

- Highway Capacity Manual, HCM-2010, Transportation Research Board, Washington.

- Kabui Simon Kiragu (2015) "Performance Analysis of the Nairobi-Thika Highway."

- Unpublished BSc Thesis, University Of Nairobi

- Martin Rogers (2003), "Highway Engineering”. Black well

- P. K. Bhuyan \& Minakshi Sheshadri Nayak (2013) "A Review on Level of Service Analysis of Urban Streets", Transport Reviews, a Transnational Trans-disciplinary Journal.

- Prasanta Kumar Bhuyan 1, K. V. Krishna Rao (2011) "Defining level of service Criteria of Urban streets in Indian context” European Transport.

- Robin Babit, Viranta Sharma, Ajay K. Dug gal (2016) "Level of Service Concept in Urban.

- Roads" International Journal of Engineering Science Invention Research \& Development; Vol. III, Issue. Roger P. Roess, Elena S. Prassas, William R. McShane. (2004) "Traffic Engineering". Third. Pearson Education Inc. 